\title{
Evolutionary conservation of bursicon in the animal kingdom is
}

\author{
Tom Van Loy ${ }^{\text {a }}$, Matthias B. Van Hiel ${ }^{\text {a }}$, Hans Peter Vandersmissen ${ }^{\text {a }}$, Jeroen Poels ${ }^{\text {a }}$, \\ Fernando Mendive $^{\mathrm{b}}$, Gilbert Vassart ${ }^{\mathrm{b}}$, Jozef Vanden Broeck ${ }^{\mathrm{a}, *}$ \\ a Animal Physiology and Neurobiology, Laboratory for Developmental Physiology, Genomics and Proteomics, \\ Zoological Institute, K. U.Leuven, Naamsestraat 59, B-3000, Belgium \\ ${ }^{\mathrm{b}}$ Institut de Recherche Interdisciplinaire en Biologie Humaine et Moléculaire (IRIBHM) and department of medical genetics, \\ Université Libre de Bruxelles, Campus Erasme, 808 Route de Lennik, B-1070 Brussels, Belgium
}

Received 14 September 2006; revised 16 November 2006; accepted 18 December 2006

Available online 27 December 2006

\begin{abstract}
Bursicon bioactivity is essential for tanning of the exoskeleton and for wing spreading behavior that occur in newly emerged adult insects. Previously, we demonstrated that in the fruit fly, Drosophila melanogaster, bursicon exists as a heterodimeric cystine knot protein that activates the leucine-rich repeats containing G protein-coupled receptor 2 (DLGR2). By performing similarity based in silico searches in genomic and complementary DNA databases, we identified bursicon homologous sequences in several protostomian as well as deuterostomian invertebrates. In the genome of the honeybee, Apis mellifera, the coding regions for bursicon cystine knot subunits are organized in a genomic locus of approximately 4 kilobase pairs. Reverse transcription PCR analysis indicates that this region likely codes for two distinct bursicon cystine knot subunits. Our results illustrate the remarkable conservation of bursicon in invertebrate species and provide an avenue for functional analyses of this hormone in a wide range of animal species.
\end{abstract}

(C) 2006 Elsevier Inc. All rights reserved.

Keywords: Genomics; Cystine knot; Bursicon; Evolution

\section{Introduction}

The importance of the neurohormone bursicon was established more than 40 years ago. By using a bursicon bioassay it was shown that nervous system extracts of multiple insect species induce tanning, i.e. melanization and sclerotization, of the exoskeleton in neck-ligated, freshly eclosed flies (Fraenkel and Hsiao, 1962; Fraenkel et al., 1966; Kostron et al., 1995). The active compound in these extracts was referred to as bursicon. Its molecular nature remained enigmatic for a very long period, indicating the complex nature of this hormone. Recently we identified

\footnotetext{
Nucleotide sequence data for the honeybee bursicon subunits are available in the EMBL database under the Accession numbers: AM420631 (bursicon subunit $\alpha$ ) and AM420632 (bursicon subunit $\beta$ ).

* Corresponding author. Fax: +32 16323902.

E-mail address: Jozef.VandenBroeck@bio.kuleuven.be (J. Vanden Broeck).
}

Drosophila melanogaster bursicon as a heterodimer composed of two $\pm 15 \mathrm{kDa}$ cystine knot proteins (Mendive et al., 2005). When co-expressed, these two cystine knot proteins, referred to as bursicon $\alpha$ (CG13419) and bursicon $\beta$ (CG15284), respectively, constitute bursicon bioactivity and, in addition, activate the fruit fly leucine-rich repeats containing $\mathrm{G}$ protein-coupled receptor 2 (DLGR2) (Luo et al., 2005; Mendive et al., 2005).

Bursicon functions downstream of a cascade of peptides that initiate and regulate the ecdysis behavioral motor program, including ecdysis triggering hormone $(\mathrm{ETH})$, eclosion hormone (EH) and crustacean cardioactive peptide (CCAP) (recently reviewed by Truman, 2005). Postecdysially, bursicon is released into the hemolymph where it initiates the tanning of the insect's cuticle. Genetic studies in the fruit fly also clearly demonstrated the regulatory role of bursicon in wing spreading behavior after adults emerge from their pupal case (Dewey et al., 2004). 
So far, bursicon activity has only been described in insects. To obtain an idea about the evolutionary conservation of this important neurohormone, we report here on an in silico screen of protostomian and deuterostomian genome and complementary DNA (cDNA) databases in the search for potential bursicon homologues. Genome sequencing and/or expressed sequence tag (EST) projects of several animal models including nematodes, insects, crustaceans and echinoderms have been completed or are currently in progress. In the particular case of the honeybee, Apis mellifera, reverse transcription PCR analysis was carried out to evaluate a former in silico prediction that in this species bursicon $\alpha$ and bursicon $\beta$ subunits might be fused into a single open reading frame (ORF). This is the first report describing bursicon related sequences that occur in non-insect animal species.

\section{Methods}

\subsection{In silico screen for cystine knot proteins related to bursicon $\alpha$ and bursicon $\beta$ subunits}

For the identification of potential bursicon homologues in distinct protostomian and deuterostomian animal phyla, genome and expressed sequence tag (EST) databases were screened using fruit fly bursicon $\alpha$ and bursicon $\beta$ cystine knot proteins as a query on the NCBI (National Center for Biotechnology Information) platform using BLAST (Basic Local Alignment Search Tool) programs (Altschul et al., 1997). For a protein query against a nucleotide database, TBLASTN was used, a program suitable for finding unannotated coding regions. Genomic sequences and/or cDNA databases (dbESTs) of several animal models including nematodes (Caenorhabditis elegans, Caenorhabditis briggsae), insects (e.g. Tribolium castaneum, Acyrthosiphon pisum), crustaceans (e.g. Daphnia arenata, Homarus americanus), echinoderms (e.g. Strongylocentrotus purpuratus) and vertebrates were included in this study.

Identified genomic regions potentially coding for bursicon subunit homologues, were further analysed by exon prediction ORF finder tool (http://www.ncbi.nih.gov/gorf) and, in addition, were conducted to the gene prediction program FGENESH based on hidden markov models, available on http://www.softberry.com. In the case of putative bursicon $\alpha$ and/or bursicon $\beta$ encoding EST sequences, the corresponding proteins were obtained by translation using BESTORF (http://www.softberry.com). Because N-terminal signal peptides are generally not conserved amongst species, and as such cannot always be identified in TBLASTN searches, each identified protein was verified for the presence of a signal sequence using the SignalP 3.0 server (http://www.cbs.dtu.dk/services/SignalP/). Searches for cysteine residues necessary to form the cystine knot structure present in bursicon proteins were performed manually. Multiple protein alignments were obtained with CLUSTALW using default settings.

\subsection{Honeybee total RNA isolation and $c D N A$ synthesis}

Larvae of the honeybee, A. mellifera, were collected and stored until use in RNAlater ${ }^{\circledR}$ solution (Ambion) to avoid RNA breakdown as much as possible. Total RNA was isolated from these larvae using the RNeasy ${ }^{\circledR}$ Lipid Tissue Mini kit (Qiagen). Before elution of the extracted RNA, an on column DNase digestion (RNase-free DNase set, Qiagen) was performed to remove traces of genomic DNA. About $4 \mu \mathrm{g}$ of purified total RNA was applied in a $20 \mu$ l First-Strand cDNA synthesis protocol with M-MLV reverse transcriptase (Invitrogen). The cDNA synthesis was primed by random hexamers and occurred at $37^{\circ} \mathrm{C}$. After cDNA synthesis, RNA complementary to the cDNA was removed by adding $1 \mu \mathrm{l}(2 \mathrm{U})$ recombinant Escherichia coli R Nase H (Invitrogen) to the sample followed by incubation for $20 \mathrm{~min}$ at $37^{\circ} \mathrm{C}$.

\subsection{Amplification of the coding regions for honeybee bursicon subunit cystine knot proteins}

Two distinct gene-specific primer sets were designed in an attempt to amplify predicted honeybee bursicon $\alpha$ and bursicon $\beta$ cDNA open reading frames (ORFs) using polymerase chain reaction (PCR): bursicon $\alpha$ forward: $5^{\prime}$ tagatctaggaggaaaagtatcctatta $3^{\prime}$; bursicon $\alpha$ reverse: $5^{\prime}$ ttattgcaaatcggaagatcgtct $3^{\prime}$; bursicon $\beta$ forward: $5^{\prime}$ tagaatctctgagcatatctttgctat $3^{\prime}$; bursicon $\beta$ reverse: $5^{\prime}$ tatttattgggatatatcaccacattt $3^{\prime}$. For each PCR, $2 \mu 1$ of prepared larval honeybee 'First-Strand cDNA' was used as template. In the case of honey bee bursicon $\alpha$, annealing temperature was $54^{\circ} \mathrm{C}$, for bursicon $\beta$ annealing temperature was $55^{\circ} \mathrm{C}$. PCR was run for 35 cycles.

PCR products were analysed by agarose gel electrophoresis and DNA fragments of the expected length were purified according to the GenElute ${ }^{\mathrm{TM}}$ Gel Extraction kit (Sigma). For sequencing purposes, purified DNA was subsequently cloned into pCR2.1 TOPO (Invitrogen) according to the manufacturer's guidelines. DNA sequencing reactions were performed with BigDye ${ }^{\circledR}$ Terminator v1.1 Cycle Sequencing kit (Applied Biosystems) and run on the ABI 3130 genetic analyser.

\section{Results and discussion}

\subsection{Reverse transcription PCR analysis and sequencing of honeybee bursicon cystine knot proteins}

Previously, we hypothesized that in honeybee, bursicon $\alpha$ and bursicon $\beta$ proteins would be encoded by a single open reading frame leading to a fusion protein (Mendive et al., 2005). However, an experimental RT-PCR approach using larval honeybee tissues did not allow us to confirm this in silico prediction (not shown). To clarify this situation, we reanalysed the genomic locus coding for honeybee bursicon according to the FGENESH program resulting in an alternative prediction of honeybee bursicon gene organization. Two distinct cystine knot proteins corresponding to bursicon $\alpha$ and bursicon $\beta$, respectively, were retrieved from this analyis (Fig. 1).

Based on this new in silico prediction bursicon specific primers were designed and applied in a RT-PCR experiment, starting from extracted honeybee larval total RNA. After cDNA synthesis, bursicon $\alpha$ and bursicon $\beta$ ORFs

Fig. 1. Evolutionary conservation of bursicon. (a) Amino acid similarity between cloned and/or predicted bursicon $\alpha$ cystine knot proteins (burs $\alpha$ ) from insects [fruit fly, Drosophila melanogaster (Drome), honeybee, Apis mellifera (Apime), red flour beetle, Tribolium castaneum (Trica) and pea aphid, Acyrthosiphon pisum (Acypi)] are compared with sequences from crustaceans [water flea, Daphnia arenata (Dapar)] and echinoderms [purple sea urchin, Strongylocentrotus purpuratus (Strpu)]. (b) Amino acid sequence similarity between cloned and/or predicted bursicon $\beta$ cystine knot proteins (burs $\beta$ ) from insects [fruit fly, Drosophila melanogaster (Drome), honeybee, Apis mellifera (Apime), red flour beetle, Tribolium castaneum (Trica) and pea aphid, Acyrthosiphon pisum (Acypi)] are compared with sequences from crustaceans [the green shore crab, Carcinus maenas (Carma) and the lobster, Homarus americanus (Homam)] and echinoderms [purple sea urchin, Strongylocentrotus purpuratus (Strpu)]. Fully conserved amino acid residues are depicted in white. All proteins share the same signature of 11 conserved cysteine residues. Blocks of similar or identical amino acids are shaded in grey. Predicted signal peptides are shown above the conserved sequences, in the upper part of each alignment. 
a
Drome burs $\alpha$ Apime burs $\alpha$ Trica burs $\alpha$ Acypi burs $\alpha$ Dapar burs $\alpha$ Strpu burs $\alpha$

Drome burs $\alpha$ Apime burs $\alpha$ Trica burs $\alpha$ Acypi burs $\alpha$ Dapar burs $\alpha$ Strpu burs $\alpha$

Drome burs $\alpha$ Apime burs $\alpha$ Trica burs $\alpha$ Acypi burs $\alpha$ Dapar burs $\alpha$ Strpu burs $\alpha$

Drome burs $\alpha$ Apime burs $\alpha$ Trica bursa Acypi burs $\alpha$ Dapar burs $\alpha$ Strpu burs $\alpha$

b Drome burs $\beta$ Apime burs $\beta$ Trica burs $\beta$ Acypi burs $\beta$ Carma burs $\beta$ Homam burs $\beta$ Strpu burs $\beta$

Drome burs $\beta$ Apime burs $\beta$ Trica burs $\beta$ Acypi burs $\beta$ Carma burs $\beta$ Homam burs $\beta$ Strpu burs $\beta$

Drome burs $\beta$ Apime burs $\beta$ Trica burs $\beta$ Acypi burs $\beta$ Carma burs $\beta$ Homam burs $\beta$ Strpu burs $\beta$

Drome burs $\beta$ Apime burs $\beta$ Trica burs $\beta$ Acypi burs $\beta$ Carma burs $\beta$ Homam burs $\beta$ Strpu burs $\beta$
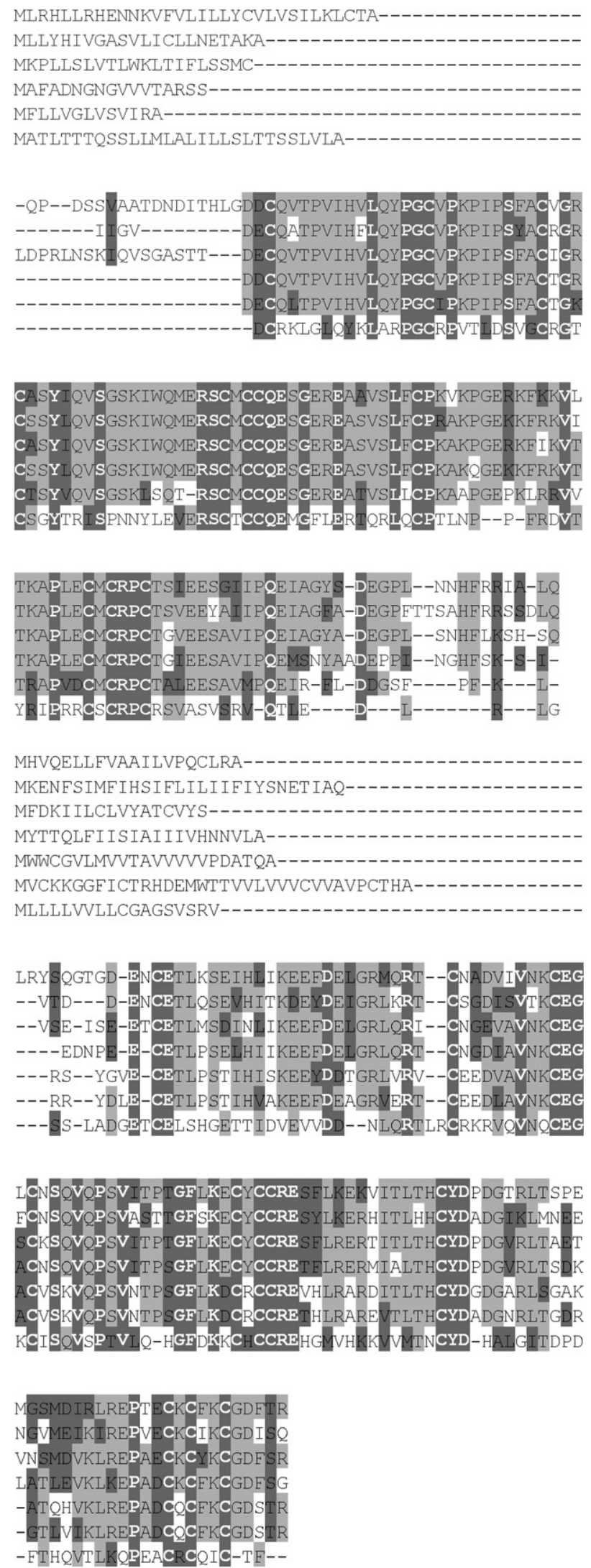

were amplified, cloned into pCR2.1 TOPO and verified by DNA sequencing. Both cloned ORFs contained a signal sequence for protein secretion and are in full agreement with the in silico predicted ORFs. We conclude that honeybee bursicon likely functions as a heterodimer rather than a multidomain cystine knot protein. 


\subsection{Bursicon $\alpha$ and bursicon $\beta$ subunit cystine knot proteins are highly conserved in insects}

The bursicon $\alpha$ and bursicon $\beta$ amino acid sequences from the fruit fly, D. melanogaster, the malaria mosquito, Anopheles gambiae, and the silkworm, Bombyx mori, have been described earlier (Mendive et al., 2005). Homologous bursicon subunit sequences, displaying high overall sequence conservation (about $80 \%$ similarity), are encoded in the genome of the red flour beetle, T. castaneum. Interestingly, in the beetle genome, the region encoding bursicon is similarly organized as in the honeybee with the bursicon $\alpha$ coding region positioned just downstream of the bursicon $\beta$ coding part, supporting the idea of a duplication event of an ancestral cystine knot encoding gene.

Analysis of insect EST databases revealed the presence of bursicon $\alpha$ transcripts in the pea aphid, A. pisum (Fig. 1) and the tsetse fly, Glossina morsitans morsitans (a partial sequence). Bursicon $\beta$ transcripts were also found in the pea aphid, A. pisum (Fig. 1). It is now clear that bursicon is well conserved in both holometabolic [such as hymenoptera (honeybee), coleoptera (beetle), lepidoptera (silkworm) and diptera (fruit fly and mosquito)] and heterometabolic [including hemiptera (aphid) and dictyoptera (cockroach, (Honegger et al., 2002))] insect orders.

We did not succeed in identifying bursicon related genes in nematodes (C. elegans, C. briggsae) or mollusk species. Because of the relative lack of genomic and cDNA sequence information from mollusks, it would be too preliminary to conclude that these animals do not contain bursicon related proteins. Moreover, a leucine-rich repeats containing $\mathrm{G}$ protein-coupled receptor (LGR), structurally related to the Drosophila bursicon receptor, is expressed in the digestive gland of the bivalve mollusk, Crassostrea gigas (Herpin et al., 2004).

The apparent absence of bursicon in the genome of nematodes might seem somewhat surprising as nematodes are believed to be phylogenetically related with other molting animals (the clade Ecdysozoa) (Aguinaldo et al., 1997). In contrast to arthropods, that express all three LGR subtypes (refered to as type A, B and C), LGRs are less expanded in nematodes. The only LGR encoded in the nematode genome is more closely related to gonadotropin/thyrotropin receptors (type A LGRs) than to the bursicon receptor (type B LGRs) (Kudo et al., 2000). Therefore bursicon might indeed not exist in nematodes. Alternatively, nematode species, such as $C$. elegans, could have lost the bursicon/LGR couple during evolution.

\subsection{The bursicon hormone subunits are present in other arthropods and even in echinoderms}

Coding sequences for putative bursicon homologues were identified when screening cDNA databases of crustaceans. The water flea, D. arenata, expresses a bursicon $\alpha$-related sequence while the lobster, H. americanus and the green shore crab, Carcinus maenas, contain bursicon $\beta$-like transcripts (Fig. 1). Nervous system extracts of the lobster,
H. americanus, display bursicon activity in the neck-ligated fly assay (Kostron et al., 1995), so it is likely that its genome also codes for a bursicon $\alpha$-related sequence. These results indicate that bursicon is not only remarkably well conserved in insects, but is also present in other classes of the arthropod phylum. This observation can trigger comparative functional studies of bursicon in this large animal group since, so far, in vivo function(s) of bursicon have only been established in insects and only concern the maturation process of the exoskeleton, as well as wing spreading behavior and development (Dewey et al., 2004; Kimura et al., 2004; Mendive et al., 2005).

Bursicon seems to be much less preserved in deuterostomians. However, in the purple sea urchin, S. purpuratus, an echinoderm marine invertebrate, putative bursicon related sequences were predicted from the genome, sharing about $45 \%$ of similarity with arthropod bursicon (Fig. 1).

\subsection{Bursicon may have rapidly evolved during chordate evolution}

With the aim of identifying bursicon homologous sequences in higher animal species, genomic and cDNA sequences from non-vertebrate chordates (e.g. the sea squirt, Ciona intestinalis) and vertebrates were screened. Although many growth factors [bone morphogenetic proteins (BMPs) and their antagonists, transforming growth factor beta (TGF $\beta$ ) family members, glycoprotein hormone subunits and extracellular matrix proteins such as mucins, reviewed in Vitt et al. (2001)] share the cystine knot structure with bursicon, none of the predicted chordate cystine knot proteins displays sufficient overall amino acid similarity to be convincingly identified as bursicon orthologues.

In humans, the closest homologues of the bursicon receptor constitute a cluster of three orphan receptors (LGRs 4-6 belonging to type B LGRs). We suggest that the ligands for these vertebrate receptors may have evolved rapidly during chordate evolution possibly to avoid promiscuous receptor activation. Therefore the similarity between bursicon and the unknown ligands for vertebrate type B LGRs might perhaps reside at the three-dimensional level, with low conservation of the primary structure. In addition, it cannot be fully excluded that other molecules, structurally unrelated to bursicon, may serve as ligands for LGRs 4-6. For instance, the human LGRs 7 and 8 (type C LGRs), although belonging to the LGR receptor subfamiliy, are activated by insulin/ relaxin-like peptides (Hsu et al., 2002).

In summary, our analysis points to the pronounced conservation of bursicon subunit proteins in insect, non-insect arthropod and echinoderm species. Future research is necessary to compare the biological function(s) of bursicon in these different animals.

\section{Acknowledgments}

We thank Sofie Van Soest for DNA sequencing. Supported by the 'Belgian programme on Interuniversity 
Poles of Attraction' (IUAP/PAI P5/30) and 'Fonds voor wetenschappelijk onderzoek' (FWO). T.V.L. and M.B.V.H. obtained a PhD fellowship from the 'Instituut voor de aanmoediging van Innovatie door Wetenschap en Technologie in Vlaanderen' (IWT).

\section{References}

Aguinaldo, A.M., Turbeville, J.M., Linford, L.S., Rivera, M.C., Garey, J.R., Raff, R.A., Lake, J.A., 1997. Evidence for a clade of nematodes, arthropods and other moulting animals. Nature 387, 489-493.

Altschul, S.F., Madden, T.L., Schaffer, A.A., Zhang, J., Zhang, Z., Miller, W., Lipman, D.J., 1997. Gapped BLAST and PSI-BLAST: a new generation of protein database search programs. Nucleic Acids Res. 25, 3389-3402.

Dewey, E.M., Mcnabb, S.L., Ewer, J., Kuo, G.R., Takanishi, C.L., Truman, J.W., Honegger, H.W., 2004. Identification of the gene encoding bursicon, an insect neuropeptide responsible for cuticle sclerotization and wing spreading. Curr. Biol. 14, 1208-1213.

Fraenkel, G., Hsiao, C., 1962. Hormonal and nervous control of tanning in the fly. Science 138, 27-29.

Fraenkel, G., Hsiao, C., Seligman, M., 1966. Properties of bursicon: an insect protein hormone that controls cuticular tanning. Science 151 , 91-93.

Herpin, A., Badariotti, F., Rodet, F., Favrel, P., 2004. Molecular characterization of a new leucine-rich repeat-containing $G$ protein-coupled receptor from a bivalve mollusc: evolutionary implications. Biochem. Biophys. Acta 168, 137-144.

Honegger, H.W., Market, D., Pierce, L.A., Dewey, E.M., Kostron, B., Wilson, M., Choi, D., Klukas, K.A., Mesce, K.A., 2002. Cellular localization of bursicon using antisera against partial peptide sequences of this insect cuticle-sclerotizing neurohormone. J. Comp. Neurol. 452, 163-177.

Hsu, S.Y., Nakabayashi, K., Nishi, S., Kumagai, J., Kudo, M., Sherwood, O.D., Hsueh, A.J.W., 2002. Activation of orphan receptors by the hormone relaxin. Science 295, 671-674.

Kimura, K.I., Kodama, A., Hayasaka, Y., Ohta, T., 2004. Activation of the cAMP/PKA signaling pathway is required for post-ecdysial cell death in wing epidermal cells of Drosophila melanogaster. Development 131, 1597-1606.

Kostron, B., Marquardt, K., Kaltenhauser, U., Honegger, H.W., 1995. Bursicon, the cuticle sclerotizing hormone-comparison of its molecular mass in different insects. J. Insect Physiol. 41, 1045-1053.

Kudo, M., Chen, T., Nakabayashi, K., Hsu, S.Y., Hsueh, A.J., 2000. The nematode leucine-rich repeat-containing, $\mathrm{G}$ protein-coupled receptor (LGR) protein homologous to vertebrate gonadotropin and thyrotropin receptors is constitutively active in mammalian cells. Mol. Endocrinol. 14, 272-284.

Luo, C.W., Dewey, E.M., Sudo, S., Ewer, J., Hsu, S.Y., Honegger, H.W., Hsueh, A.J.W., 2005. Bursicon, the insect cuticle-hardening hormone, is a heterodimeric cystine knot protein that activates $G$ protein-coupled receptor LGR2. Proc. Natl. Acad. Sci. USA 102, $2820-2825$.

Mendive, F.M., Van Loy, T., Claeysen, S., Poels, J., Williamson, M., Hauser, F., Grimmelikhuijzen, C.J., Vassart, G., Vanden Broeck, J., 2005. Drosophila molting neurohormone bursicon is a heterodimer and the natural agonist of the orphan receptor DLGR2. FEBS Lett. $579,2171-2176$.

Truman, J.W., 2005. Hormonal control of insect ecdysis: endocrine cascades for coordinating behavior with physiology. Vitam. Horm. 73, $1-30$.

Vitt, U.A., Hsu, S.Y., Hsueh, A.J., 2001. Evolution and classification of cystine knot-containing hormones and related extracellular signaling molecules. Mol. Endocrinol. 15, 681-694. 